\title{
Meeting and Notices
}

PLEASE NOTE: Information regarding Meetings, Conferences, etc. for publication in the Journal should be notified to the Editorial Secretary at Wessex Nuffield Hospital at least three months prior to the event.

'Hands on' Anatomical Workshops in Neurosurgery 1999 March 1999-November 1999, Hill Surgical Workshop, The Royal College of Surgeons of England, 35-43 Lincoln's Inn Fields, London WC2A 3PN. Further information from: Sophie Mitchell. Tel: +44 (0) 171 312 6693; Fax: + 44 (0) 171973 2118; e-mail: smitchell@rcseng.ac.uk

\section{5th Annual Scientific Conference of the American Paraplegia Society}

7-9 September 1999, Riviera Hotel, Las Vegas, Nevada. Contact APS, 75-20 Astoria Boulevard, Jackson Heights, NY 11370-1177, USA. Tel: (718) 803-3782; Fax (718) 803-0414.

Deadline for submission of papers and posters: 15 January 1999

\section{IAPMR International Conference 2000}

6-8 January 2000, New Delhi, India. For further details please contact: Dr U Singh, Organising secretary, Dept. of Physical Medicine and Rehabilitation, AIIMS, Ansari Nagar, New Delhi, 110029 India. Tel: +91 11 659 4916, 659 3232; Fax: + 9111686 2663; e-mail: usingh@medinst.ernet.in; Telegram: MEDINST, New Delhi

\section{8th Course for Percutaneous Endoscopic Spinal Surgery} and Complementary Techniques

20-21 January 2000, Hospital Pflegi-Neumunster, Zollikerberg/Zurich, Switzerland. Topics: percutaneous intradiscal, foraminal and peridural endoscopic procedures, seeing instruments. With Hands-on workshop and industrial boot exhibition. Coordinator: PD Dr.med.Hj.Leu, Prisma Spine Unit, Spital Pflegi-Neumunster, CH-8125 Zollikerberg/Zurich, Switzerland. Fax: +41 13912438

\section{Scientific Meeting of the American Spinal Injury} Association (ASIA)

14-16 April 2000, Chicago, Illinois, USA. For further details please contact: Lesley M Hudson MA, Clinical Meeting Coordinator, American Spinal Injury Association, 2020 Peachtree Road, NW Atlanta, GA30309, USA. Tel: + 1404355 9772; Fax: + 1404355 1826; Website: www.asia-spinalinjury.org

\section{The First Interdisciplinary Congress on Spinal Surgery (World Spine 1)}

27 August-1 September 2000, Berlin. All major topics related to Spinal Surgery will be covered: Neurosurgery, Orthopaedic Surgery, Minimally Invasive Surgery,
Radiology, Rehabilitation Medicine, Spine Research, Pain Therapy and related fields. Further information from: Mario Brock, MD, Congress President, Universitätsklinikum Benjamin Franklin, Neurochirurgische Klinik, Hindenburgdamm 30, D-12200 Berlin, Germany. Tel: + 49308445 2531; Fax: + 493084453569

\section{9th Annual Scientific Meeting of the International Medical Society of Paraplegia}

3-5 November 2000, Sydney, Australia. Topics: 1. Respiratory insufficiency including ventilator dependency and sleep apnoea; 2. Spinal cord injury in the elderly: Acute and Ageing; 3. Clinical trials and applied technology; 4. Pain; 5. Exercise physiology. Further information from: International Society of Paraplegia, Conference Action Pty Ltd, PO Box 1231, North Sydney, NSW 2059, Australia. Tel: + 6129956 8333; Fax: + 6129956 5154; e-mail: confact@conference action.com.au

\section{Scientific Meeting of the American Spinal Injury Association (ASIA)}

18-20 May 2001, Long Beach, California, USA. For further details please contact: Lesley M Hudson MA, Clinical Meeting Coordinator, American Spinal Injury Association, 2020 Peachtree Road, NW Atlanta, GA30309, USA. Tel: +1 404355 9772; Fax: + 1404 355 1826; Website: www.asia-spinalinjury.org

\section{1st World Congress of the International Society of Physical and Rehabilitation Medicine}

7-13 July 2001, Amsterdam RAI Congress Center, The Netherlands. Further information from: Congress Secretariat: Eurocongres Conference Management, Jan van Goyenkade 11, 1075 HP Amsterdam, The Netherlands. Tel: + 31 (0)20-679 34 11; Fax: + 31 (0)20-673 73 06; e-mail: eurocongres@rai.nl

\section{Scientific Meeting of the American Spinal Injury Association (ASIA)}

3-7 May 2002, Vancouver British Columbia, Canada (in conjunction with IMSOP). For further details please contact: Lesley M Hudson MA, Clinical Meeting Coordinator, American Spinal Injury Association, 2020 Peachtree Road, NW Atlanta, GA30309, USA. Tel: + 1404355 9772; Fax: + 1404355 1826; Website: www.asia-spinalinjury.org 


\section{Spinal Cord Prize 1999}

The Spinal Cord Prize has been awarded to Dr SR Kelly, for his paper entitled 'The role of intestinal stoma in patients with spinal cord injury'.

\section{Académie Européenne de Médecine de Réadaptation}

\section{AWARD 1999}

The annual prize of the European Academy of Rehabilitation Medicine of 10.000.-Swiss Francs will be awarded for an original work about a rehabilitation subject or for a project to continue research on a previous study.

The text or protocol must be sent (in English or in French) with an abstract in both languages (5 copies) to the Secretary before September 1, 1999.

\section{Secretary}

Professeur Alex CHANTRAINE

Hôpital Cantonal Universitaire (Beau-Séjour)

1211 Genève 14 (Suisse)

\section{Call for Papers and Posters}

46th Annual Scientific Conference of the American Paraplegia Society, September 5-7, 2000, Riviera Hotel, Las Vegas, Nevada. Contact APS, 75-20 Astoria Boulevard, Jackson Heights, NY 11370-1177, USA, Tel: (718) 803-3782, Fax: (718) 803-0414.

Deadline for submission is January 14, 2000. 


\section{THE VOLVO AWARDS FOR LOW BACK PAIN RESEARCH 2000}

In order to encourage research in low back pain, the Volvo Company also this year has sponsored three prizes of USD 10.000 each. Awards will be made competitively on the basis of scientific merit in one or more of the following three areas:

1. Clinical studies

2. Bioengineering studies

3. Studies in other basic science areas

Papers submitted for the contest must contain original material, not previously published or submitted for publication. A multiple authorship is acceptable. The manuscript, in the English language, should be in the form of a complete report, including original illustrations (please note: marked with names!); not exceeding 15 typewritten pages - references and tables can be added; double-spaced; typed text should not be smaller than Times 12 points; and in a form suitable for submission as an original paper to a scientific journal. Ethics committee approval is necessary for all animal studies as well as controlled clinical studies. One original and 5 copies of each paper in full - including illustrations - must reach the address given below not later than November 15, 1999. Accordingly, articles sent by Fax will not be accepted. Do not forget to give complete address with telephone number and Fax number. Winners will be informed mid January 2000.

One of the authors should be prepared, at his own expenses, to come to Adelaide, Australia, at the time of the meeting of the International Society for the Study of the Lumbar Spine, April 913,2000 , to present the paper and to receive the award.

The board of referees will be chaired by the undersigned and will contain members from the fields of clinical medicine, bioengineering and biochemistry.

Please direct all correspondence to:

Professor Alf Nachemson

Department of Orthopaedics

Sahlgrenska University Hospital

S-413 45 Göteborg, Sweden 